\title{
Impact of the first wave of COVID-19 on the employment of older people in Latvia, the Baltic States and Europe
}

\author{
Olga Rajevska $^{1, *}$, Agnese Reine ${ }^{2}$, and Diana Baltmane ${ }^{1}$ \\ ${ }^{1}$ Riga Stradins University, Statistics Unit, Riga, Latvia \\ ${ }^{2}$ Riga Stradins University, Faculty of Law, Riga, Latvia
}

\begin{abstract}
The study bases on the SHARE Wave 8 COVID-19 Survey conducted in June-August 2020 in 26 European countries and Israel via CATI. The association between health status of older workers and their involvement into labour market in Latvia is the strongest in Europe. In the short term, the first wave of the infection outbreak affected the employment of older population in the Baltic States to much lesser extent than in most of participating countries. The proportion of those workers who experienced unemployment, lay-off or closure of business, as well as changes in the number of working hours was considerably lower than average values. The branches with traditionally high share of older workers (education, healthcare, agriculture, administrative services) were least affected by lockdown measures. Remote work from home in the Baltic States as well as combining work from home with usual work place was lower than the European average. The existing labour legislation in Latvia does not ensure sufficient protection of workers' rights and health in the situation of remote work.
\end{abstract}

\section{Introduction}

Fuelled by the population ageing both due to natural decrease and to extensive outmigration of people in younger age groups to Western European countries, elderly workers have become an important part of labour market in Latvia, as well as in the other Baltic States. As was demonstrated in our recent work (1), promoting active and healthy ageing has become a prominent part of political agenda in Latvia, Estonia and Lithuania, backed by the adoption of special national programmes aimed at increasing the employability of older population groups and the allocation of resources to these programmes, including financing from European Structural Funds. To support employment of the elderly, vocational and lifelong learning activities are supported to provide possibility for older people to adapt to labour market and enhance their skills. Labour laws in Latvia, Estonia and Lithuania oblige employers to prevent the age-based discrimination ensuring longer employability of the elderly. However, elderly people might encounter difficulties in finding a new job or keeping the current one, as employers tend to have a prejudice that older workers might not be as productive as younger employees might. They are less flexible for changes and it is more problematic for

\footnotetext{
*Corresponding author: olga.rajevska@rsu.lv
} 
them to expand their skills to different sectors (2). Prolonged employment is considered to be of the utmost importance for the improvement of people's well-being (3).

Earmarked nationwide programmes facilitating the measures aimed at enabling older workers to remain longer in the labour market are in place in all three Baltic States. They include 'Development of Comprehensive Active Ageing Strategy for Longer and Better Working Lives' (Latvia), 'Increasing Employment for 2014-2020' (Lithuania). In Estonia, employment of the workers aged 50 years and older has already been one of the priorities on public policy agenda for a long time, represented in such policy documents as 'Welfare development plan' and 'Lifelong learning', and 'Strategy 2035'. Furthermore, a special scheme for retraining $50+$ people in labour employment has been developed.

The employment rates among the population of pre-retirement and retirement age are steadily increasing in Latvia, as well as in the other two Baltic countries. In the list of 26 European countries included into the Active Ageing Index (AAI), Estonia has the highest score in the domain of employment (the AAI calculation comprises four domains: employment, social participation, independent, healthy and secure living, and capacity and enabling environment). Latvia and Lithuania have relatively high scores in this domain either - they share the fourth and the fifth places in the ranking. However, the ranks received by the Baltic States in the other domains are not that high, in particular those relating to the health situation of the elderly (4). Compared to their peers from other European countries, older people in the Baltic countries are indeed more active, but less healthy. The outbreak of the new coronavirus made this group of population even more susceptible to health risks.

Looking at the group of working pensioners in Latvia, according to the data provided by the Bank of Latvia, they are mostly employed in such fields as education, administrative services, healthcare and agriculture (5). The proportion of pensioners is also higher in a number of small sectors, such as in art and operations with real estate, as well as in water supply and waste management. Mostly, these professions were not under the risk of losing their jobs due to COVID-19 infection wave, in contrast to representatives of hospitality and catering industries, tourism and entertainment, where younger workers make the majority. Nonetheless, many employees had to change their everyday working routines radically by switching to remote or hybrid way of work.

\section{Results and discussion}

The quantitative analysis in the study is based on the Survey of Health, Ageing and Retirement in Europe (SHARE) special COVID-19 Wave, which was carried out with the means of computer-assisted telephone interviews (CATI) in 26 European countries and Israel in JuneAugust 2020 (6). The questionnaire studied how population aged 50 years and older coped with socioeconomic and health-related impact of the COVID-19 pandemic. To assess the influence of the first coronavirus wave on employment in older age groups in Latvia and across Europe we applied the methods of descriptive statistics and the analysis of legislative acts.

Immediately before the COVID-19 emergency, $37.1 \%$ of all Latvian respondents over age 50 were engaged in employment (full time or part time wage earners or self-employed). Quite close ratios were detected among respondents in the other two Baltic countries $(41.8 \%$ in Estonia and $38.0 \%$ in Lithuania). However, the respective employment indicators provided by the Eurostat, which calculates them basing on the EU Labour Force Survey (LFS), are higher for all three countries: the LFS data return $41.5 \%$ in Latvia, $45.0 \%$ in and $43.2 \%$ in Lithuania as employment rates in the age group 50+ for 2019. Other participating countries also demonstrated discrepancies between SHARE and LFS employment rates. In majority of them (e.g., Germany, France, Poland), similarly to the Baltic States, SHARE data provided lower proportions of older people in employment, but for some countries (such as Denmark, 
Finland and Sweden) LFS employment rates were lower. It can be attributed to the differing methods of selecting respondents for the national samples, as well as to the differing algorithms of weighting. We, nonetheless, consider that the SHARE data can be used to assess to what extent the individual respondents' employment situation was affected by the coronavirus pandemic.

First, we analysed the relationship between the health condition of individual respondents measured on a self-assessment five-point scale (from "poor" to "excellent", "caph003_") and their employment status ("caep805_"). According to the data from the most recent SHARE survey (8th wave, data collected in 2020), almost in all participating countries there was a statistically significant positive correlation between these two variables. It was, however, rather weak, in some countries even close to negligible. Latvia returned the highest correlation 0.402 (calculated as point-biserial non-parametric Spearman's correlation coefficient), but in no other country the value of the coefficient exceeded 0.4 . The second place was occupied by Slovakia (0.387), followed by Estonia (0.394) and Lithuania (0.348). The vast majority of the other countries had their respective coefficient between 0.2 and 0.3 , and seven countries (the Netherlands, Spain, France, Belgium, Luxembourg, Switzerland, Malta and Portugal) had extremely weak correlation ranging between 0.1 and 0.2 . It makes us conclude that physical ability to work for the older population groups is closer linked to their actual employment status in the Baltic region than it is in other parts of Europe. It may also mean more pronounced consequences of the COVID-19 and the limitations imposed on businesses and social life during the extraordinary situation to employability of the elderly in three Baltic States compared to other EU member states. A stronger relationship between health and employment can also give a warning of an insufficient number of inclusive job places for people with health problems in the respective countries. Finally, it may be caused as well by a stronger need in work as a means of making ends meet in the absence of satisfactory social protection for the elderly (7).

The further analysis was made only for the respondents aged 50 years and older who were in employment before the outbreak of the virus. There were several questions in the SHARE questionnaire concerning their further status. One of the questions asked whether the respondent faced "unemployment, laid off or business closed due to COVID-19". In total, $20.5 \%$ of all respondents gave positive answer, but the proportions varied a lot among the countries (see Fig. 1).

The largest share of positive answers - more than one third of all participants - was observed in France (39\%), followed by Greece and Cyprus (36\% and 35\% respectively). The Baltic States were affected less than most of the other countries, returning relatively low figures: $18 \%$ in Lithuania, $10 \%$ in Estonia and only $6 \%$ in Latvia. Only two countries demonstrated the proportions lower than Latvia. These were Poland and the Netherlands $(5 \%$ in both of them). In majority of countries (16 out of 27), men were less affected than women were. Among the Baltic States, in Estonia and Lithuania, both genders were hit rather similarly $-9.6 \%$ of men compared to $10.7 \%$ of women in Estonia, and $18.1 \%$ of men compared to $18.6 \%$ of women in Lithuania. In Latvia, the gender difference was much more pronounced: $9.2 \%$ of men experienced ceasing of employment compared to only $3.5 \%$ of women (this was the second widest gap between the genders after Czech Republic, where 14.6\% men and $3.1 \%$ of women answered positively to this question).

A recent study (8) revealed that job loss was associated with females, lower education and household income, and older age in women. Job loss appeared to affect disproportionally already economically vulnerable individuals, raising concerns about the exacerbation of social inequalities.

Except from complete cessation of work, many participants (in total, 26.2\%) had their working hours reduced after the outbreak of the infection (Fig. 2). 


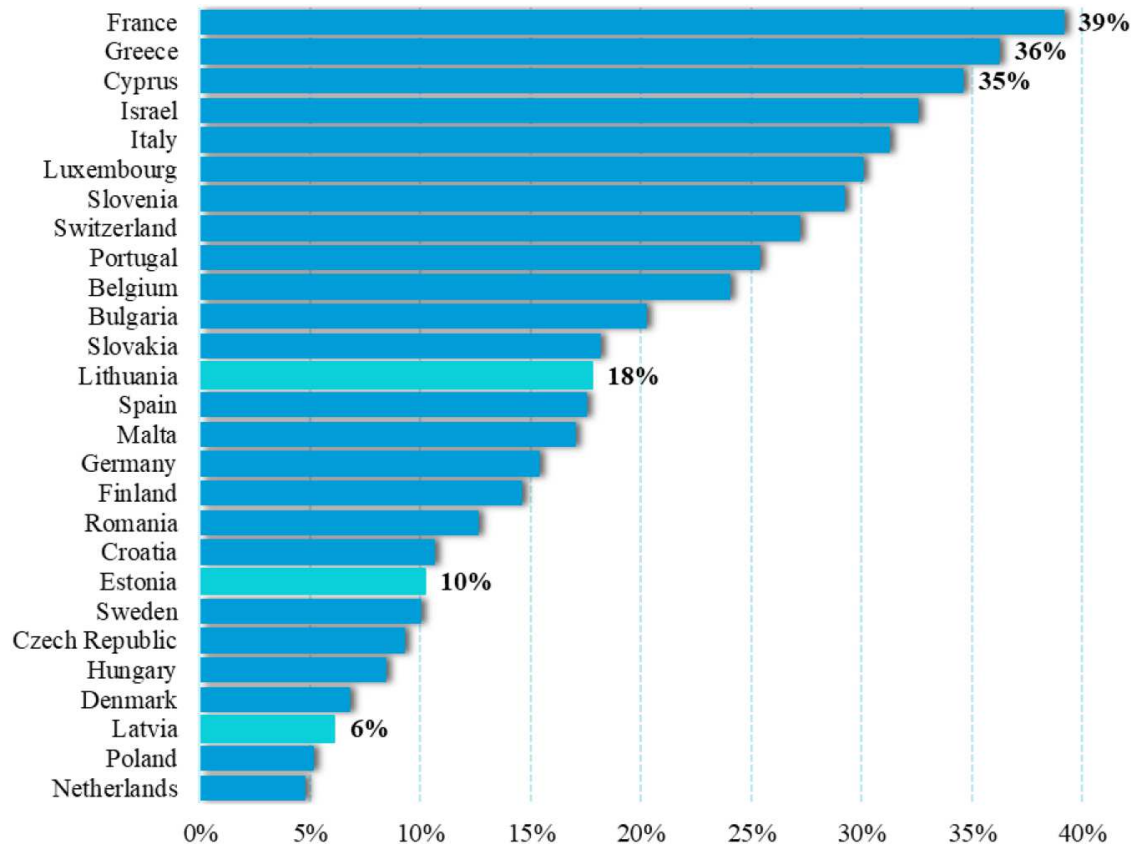

Figure 1. Proportion of "Unemployed, laid off or business closed due to COVID-19" in age group 50+.

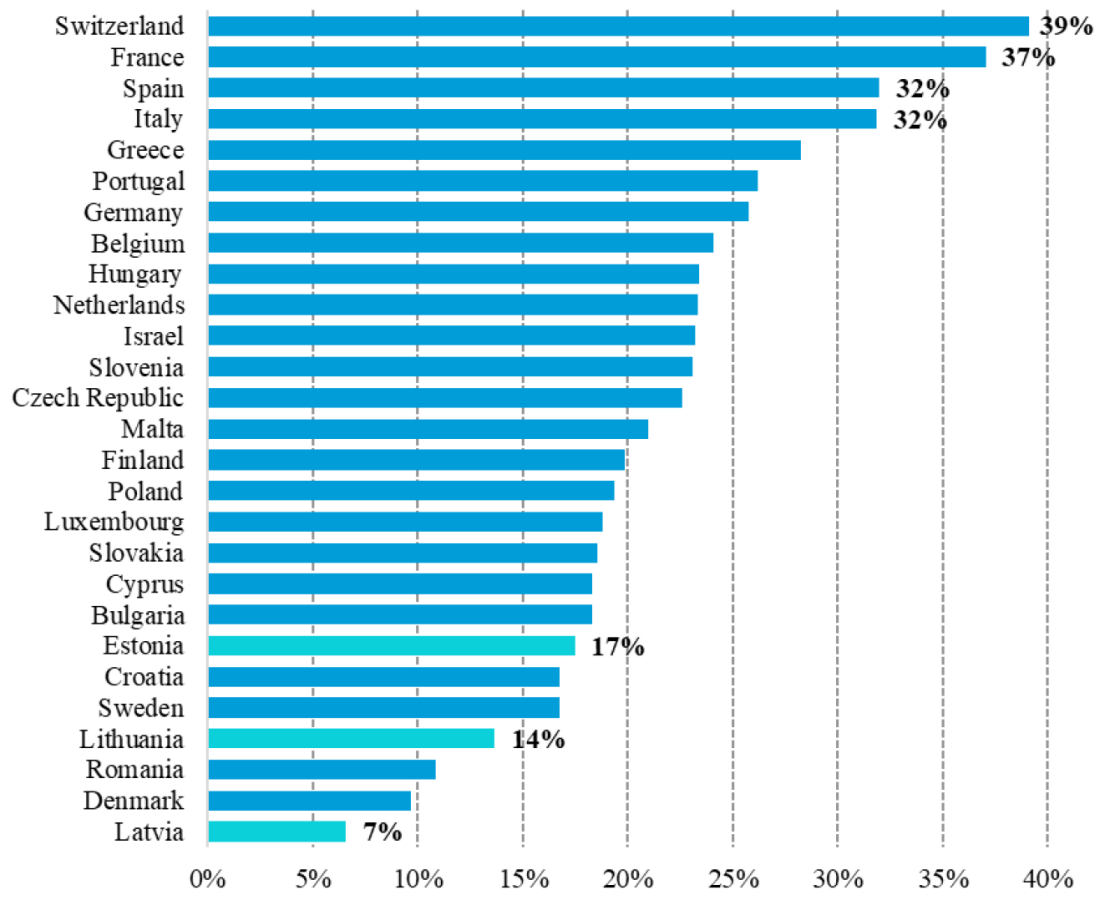

Figure 2. Proportion of "Reduced working hours after the outbreak of COVID-19" in age group 50+. 
More than one third of the employed in the age group 50+ in Switzerland (39.1\%) and France $(37.0 \%)$ faced reduced working hours. In Spain and Italy, the share of such people was slightly below one third (32.0\% and $31.9 \%$ respectively). The Baltic States were in the bottom of the list: $17.5 \%$ in Estonia (15.9\% of men and $18.8 \%$ of women), $13.7 \%$ in Lithuania (15.5\% of men and $12.2 \%$ of women) and only $6.6 \%$ in Latvia (5.0\% of men and $7.9 \%$ of women), which was the lowest ratio among all participating countries.

It was noted (9) that education had a clear mitigating role for the negative labour market effects of the pandemic. A level of education lower than high school is associated to a higher probability to stop working and a larger probability to undergo longer work interruptions.

Alongside the respondents, whose workload had ceased or decreased, there were also many respondents, whose working hours had increased. Most likely, these were the healthcare and social care professionals, pedagogical staff, and some other professions the need in which intensified with the pandemic. Their share is less than that of those whose work has decreased - on average, in all countries they were $14.6 \%$ varying from $2 \%$ in Hungary to $25 \%$ in France (Fig. 3). In most of the countries (in 23 of 27), women more often reported increase in their working hours than men. It is also interesting to note that the countries, which had the highest percentages of people with decreased working hours (Switzerland, France, and Spain), also had the highest percentages of people with increased working hours.

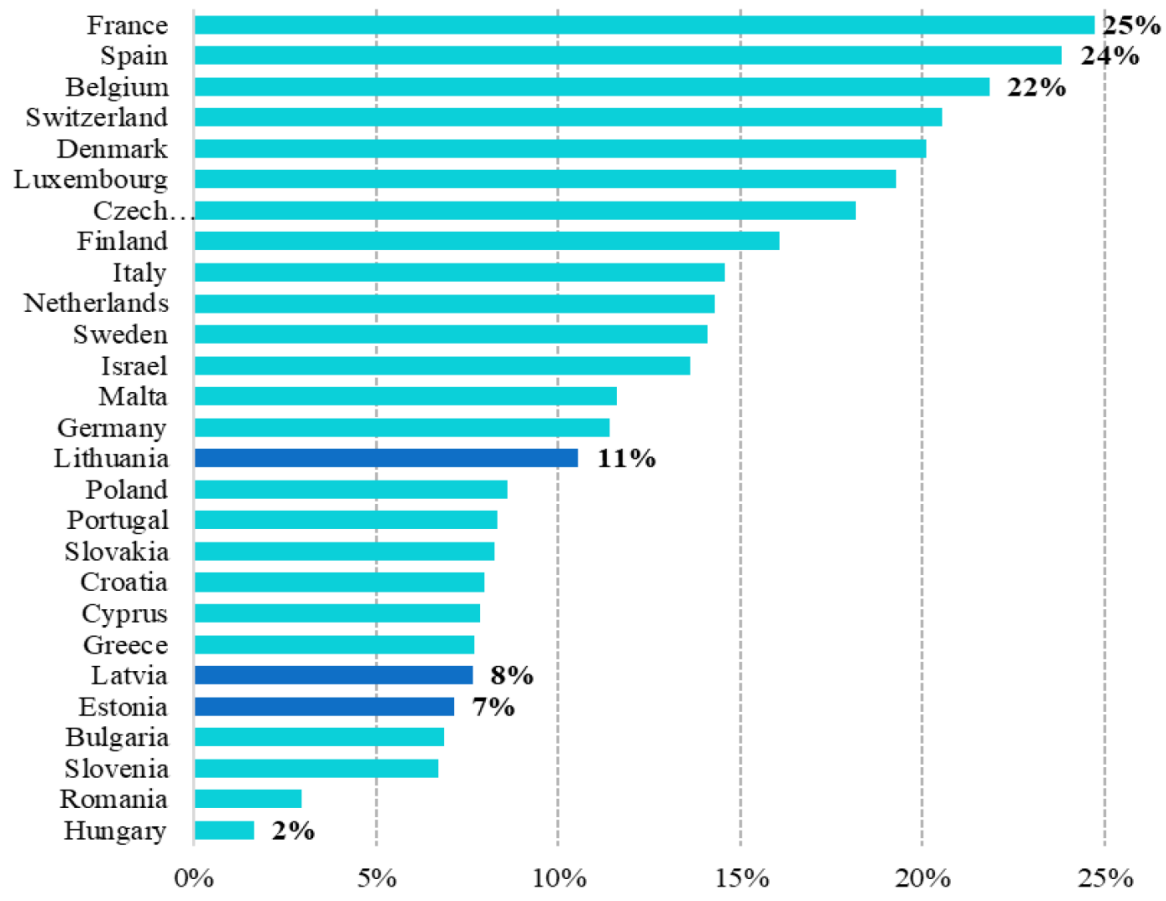

Figure 3. Proportion of "Increased working hours after the outbreak of COVID-19" in age group 50+.

Again, the Baltic States are closer to the end of the list. In all three countries the share of women who experienced increase in their working hours is substantially higher than the share of men: Estonia $-4.5 \%$ of men and $9.3 \%$ of women, Latvia $-4.4 \%$ of men and $10.3 \%$ of women, and Lithuania $-5.8 \%$ of men and $14.3 \%$ of women.

As concerns the work place since outbreak, for majority of the people (52\% in total in all countries that participated in the survey) the outbreak of the COVID-19 brought no 
changes, and they continued to work at their usual work places (Fig. 4). Altogether, in 16 countries more than half of the respondents kept working at the usual work place, while in 11 countries there were less than $50 \%$ of such workers. The most radical changes were detected in Luxembourg (only $27.2 \%$ remained at their usual work places), France (30.7\%), and Italy $(36 \%)$; on the other hand, in Bulgaria $80 \%$ of people aged $50+$ continued working at the usual work place.

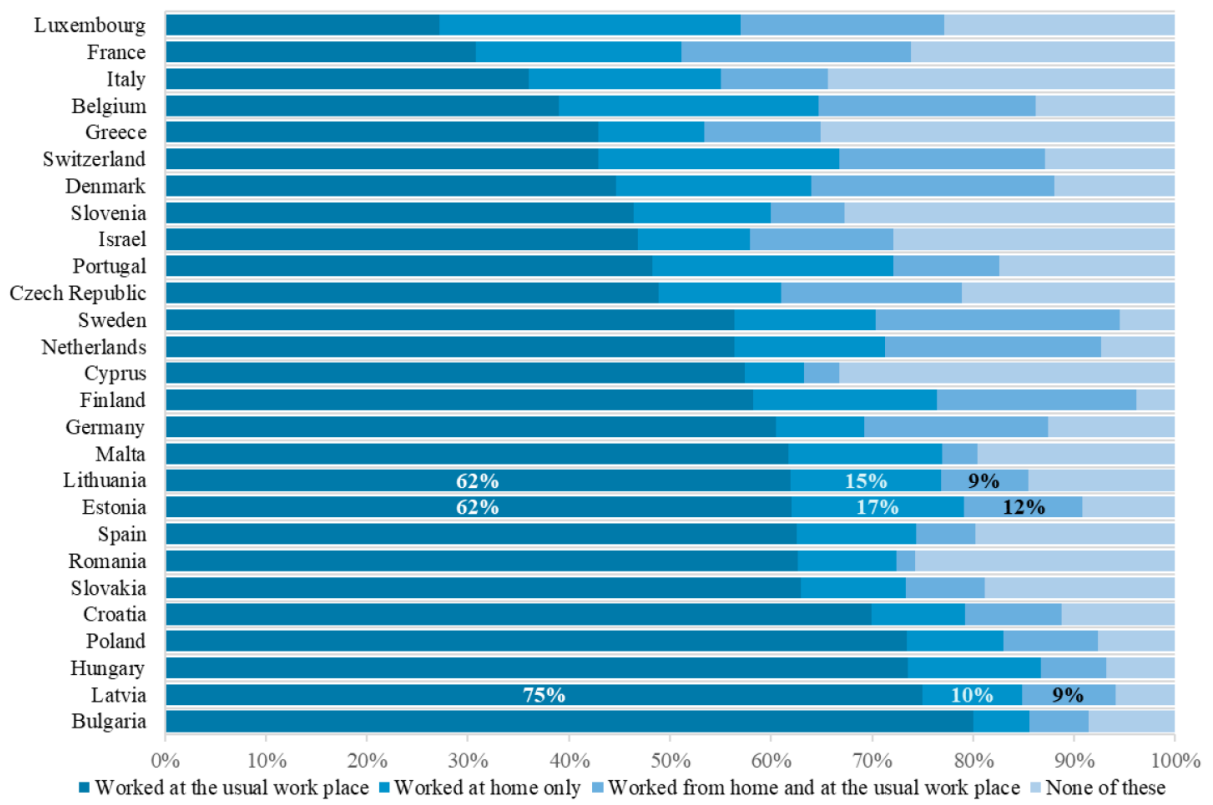

Figure 4. Place of work since the outbreak of COVID-19 in age group 50+.

$75 \%$ of Latvian and $62 \%$ of Estonian and Lithuanian respondents worked at their usual work places during the first wave of COVID-19 in spring 2020.

At the same time, a substantial share of the employed started to work remotely from home or to combine working from home with work at the usual work place. In total, the answer "at home only" was chosen by $14.3 \%$ of the respondents (approximately one out of seven), ranging from $5.6 \%$ in Bulgaria to $29.9 \%$ in Luxembourg. The respective proportions in the Baltic States made $9.8 \%$ in Latvia, $17.1 \%$ in Estonia and $14.9 \%$ in Lithuania.

Combining working remotely from home with the work at the usual work place was characteristic to $15.4 \%$ of all respondents. The most common use of such work form was observed in Sweden (24.2\%), and the least popular it was in Romania (1.8\%). In the Baltic States, it was also found less frequently than on the average: $9.2 \%$ of the participants in Latvia, $11.7 \%$ in Estonia and $8.6 \%$ in Lithuania.

\section{Legal regulation of remote work in Latvia}

As was demonstrated above, the data show that in Latvia, compared to many other European countries, only a small share of the respondents started to work remotely during the first wave of the COVID-19 pandemic in spring 2020. However, this abrupt change of everyday habits and daily routines was very touchy to both the employees and their employers. The situation 
revealed the unpreparedness of all parties, and, specifically, lack of proper legal regulation of such a work form.

Companies and organisations, whose employees started working remotely, realised not only the necessity of adjusting the technical aspects of distant work (stable internet connection, software for online conference calls, etc.). They faced also the aspects of being able to ensure all labour protection requirements, when people work not from the safely equipped working places but at their homes beyond the direct control of the employer.

It became clear that it is important to define in legal acts, what a remote work is and what conditions should be ensured in cases when employees work remotely. In particular, it is essential to ensure the compliance of remote working places with the safety and ergonomic working environment requirements, which is specifically important for older employees since an inappropriate working environment may cause serious health damage to people in the age group 50+. The labour law implies an obligation on the employer to provide an appropriate working environment when the employee performs work at the employer's premises, but the employer must also comply with the same labour protection requirements when the work is performed remotely.

In Latvia, during the first wave of the COVID-19, the legal framework for labour relationships did not include any definition of the remote work, except providing in general terms a possibility for the employer to agree with the employee on the place where the work is carried out. On July 1st, 2020, the amendments to the Labour Protection Law (10) came into force and, together with those amendments, the legal clarification of the concept of "remote work" was also included. Moreover, by these amendments it was determined that an employee who works remotely should in a cooperation with the employer assess the risks of the work environment.

Nevertheless, these amendments did not fully resolve all legal issues related to remote work. In 2021, the legislator elaborated extra amendments to the Labour Law (11) on the coverage of employee costs of remote work, as well as further clarification and a common understanding of the concept of remote work within the meaning of the Labour Law. The amendments were adopted on 27 May 2021 and will come into force starting from 1 August 2021.

With the continual spread of the virus of COVID-19 and in a proactive assessment of future prospects, the legislator's obligation is to modernise the legal framework, specifically by considering the ways of effective ensuring the enforcement of labour protection requirements.

\section{Conclusions}

The association between health status of older workers and their involvement into labour market in Latvia is the strongest in Europe. The other Baltic States also demonstrate high ranks on that scale. In the future, a closer link between employment and health in the region may entail long-term effects of COVID-19 pandemic on employment of the elderly. Thus, it might deteriorate Active Ageing Index scores of Latvia, Estonia and Lithuania.

In the short term, speaking on purely quantitative indicators of employment, in general, the first wave of the infection outbreak affected the employment of older population in Latvia and other Baltic states to a much lesser degree than in many other countries. The proportions of those workers who experienced unemployment, lay-off or closure of business was considerably lower than in the regions of Europe that were most hit by the infection.

Less expressed changes in the number of working hours were observed in the Baltic States, as well. The branches with traditionally high share of older workers (education, healthcare, agriculture, administrative services) were least affected by lockdown measures. 
Remote work from home in the Baltic States as well as combining work from home with usual work place was lower than the European average.

The existing labour legislation in Latvia does not ensure sufficient protection of workers' rights and health in the situation of remote work. When employees are working remotely, it is the obligation of the employer to ensure that the environment of employee is compliant with all requirements set out in the legal acts. That is particularly important for employees in the age group 50+ who are much more vulnerable to disabilities.

A more severe and prolonged second wave of the infection in 2020-2021 with stricter lockdown measures in all three Baltic countries undoubtedly had a more devastating immediate impact on employment in all age groups, that is not possible to quantify yet. Potential subsequent waves and the long-term effects of the disease and the stressful situation will worsen the health of workers, in particular, the oldest ones, which will also have an impact on their working careers in the future. The effect should be closely monitored and the necessary preventive and mitigating measures put in place.

The study was performed within the project "Impact of Covid-19 on aging populations in Latvia: recommendations for mitigation health and social effects and preparedness for potential crises in the future" in the framework of VPP-COVID-2020/1-0011 "Impact of COVID-19 on health care system and public health in Latvia; ways in preparing health sector for future epidemics".

\section{References}

[1] O. Rajevska, A. Reine and D. Baltmane, Economic Science for Rural Development 55(tbc) (2021 - to be published)

[2] M. Bussolo, J. Koettl and E. Sinnott. Golden Aging: Prospects for healthy, active, and prosperous aging in Europe and Central Asia. The World Bank. Available at: https://doi.org/10.1596/978-1-4648-0353-6 (2015)

[3] E. Calvo, Does working longer make people healthier and happier? Issue Brief WOB, 2 (2006)

[4] UN Economic Commission for Europe, 2018 Active Ageing Index. Analytical Report (2019)

[5] I. Opmane, Latvijā trūkst darbaspēka. Vai pensionāri var pal̄̄dzēt? The analytical website of the Bank of Latvia "Makroekonomika.LV" (15/03/2018). Available at: https://www.makroekonomika.lv/latvija-trukst-darbaspeka-vai-pensionari-var-palidzet

[6] A. Börsch-Supan, Survey of Health, Ageing and Retirement in Europe (SHARE) Wave 8. COVID-19 Survey 1. Release version: 0.0.1. beta. SHARE-ERIC. Data set. DOI: 10.6103/SHARE.w8cabeta.001 (2020)

[7] O. Rajevska and F. Rajevska, PenCon 2018 Pensions Conference,19-20 April, 2018, Lodz, Poland, 233-242 (2018)

[8] K. Jiskrova, M. Bobák, H. Pikhart and A. Ksinan, JECH (online first), DOI: 10.1136/jech-2021-216715 (2021)

[9] A. Brugiavini, R.E. Buia and I. Simonetti, Occupation and Working Outcomes during the Coronavirus Pandemic. SHARE Working Paper Series 60-2021, Munich Center for the Economics of Aging (MEA). Munich. DOI: 10.17617/2.3291840 (2021)

[10] Latvijas Republikas Darba aizsardzības likums [Labour Protection Law of the Republic of Latvia]. Available at: https://likumi.lv/ta/id/26020

[11] Latvijas Republikas Darba likums [Labour Law of the Republic of Latvia]. Available at: https://likumi.lv/ta/id/26019 